\title{
Borderline ovarian tumours-patterns of recurrence and fertility outcome
}

\author{
Dhanya Dinesh ${ }^{1 *}$, Rema Prabhakaran Nair ${ }^{2}$, Suchetha Sambasivan $^{2}$, \\ Aswin Kumar ${ }^{3}$, Iqbal M. Ahamed ${ }^{2}$
}

${ }^{1}$ Consultant Gynec Oncosurgeon, Believer's Church Medical College and Hospital, Tiruvalla, Kerala, India ${ }^{2}$ Department of Surgical Oncology, ${ }^{3}$ Department of Radiation Oncology, Regional Cancer Centre, Trivandrum, Kerala, India

Received: 22 July 2017

Received: 29 August 2017

Accepted: 01 September 2017

\section{*Correspondence:}

Dr. Dhanya Dinesh,

E-mail: dhanyadinesh13@gmail.com

Copyright: (C) the author(s), publisher and licensee Medip Academy. This is an open-access article distributed under the terms of the Creative Commons Attribution Non-Commercial License, which permits unrestricted non-commercial use, distribution, and reproduction in any medium, provided the original work is properly cited.

\begin{abstract}
Background: The aim of the study was to evaluate the factors affecting recurrence and prognosis in patients with borderline ovarian tumours and to assess the fertility outcome in women treated with conservative surgery.

Methods: Fifty-six patients diagnosed with borderline ovarian tumours during the period between January 2005 and December 2009 in Regional Cancer Centre (RCC), Thiruvananthapuram were included. Patients were followed till December 2012.

Results: Median follow up period was 52.5 months. The mean age at diagnosis was 33.5 yrs. Histopathology was serous in $41.1 \%$, mucinous in $57.1 \%$, and endometrioid in $1.8 \% .48$ patients $(85.7 \%)$ had stage I disease, 2 patients (3.6\%) had Stage II disease and 6 patients $(10.7 \%)$ had stage III disease at diagnosis. 11 patients $(19.6 \%)$ had bilateral tumours of which $7(63.6 \%)$ were serous and 4 were mucinous. 27 patients $(48.2 \%)$ underwent fertility sparing surgery of which 13 patients underwent cystectomy and 14 underwent ovariotomy. 29 patients $(51.78 \%)$ underwent complete surgery including hysterectomy, bilateral salpingo oopherectomy and omentectomy. $14.3 \%$ of patients had microinvasive disease and $14.3 \%$ had micro papillary disease on histopathology. 9 patients $(16.1 \%)$ had peritoneal implants of which 1 was invasive and 8 were non-invasive. Recurrence rate in the entire study group was $30.4 \%$, $14.28 \%$ among patients undergoing complete surgery, $28.57 \%$ among patients undergoing adnexectomy and $69.2 \%$ among patients undergoing cystectomy.

Conclusions: Univariate analysis showed a significant association between micropapillary histology, peritoneal implants and recurrence. On multivariate analysis, only peritoneal implants were found to be independently associated with recurrence.
\end{abstract}

Keywords: Borderline ovarian tumours, Recurrence, Risk factors

\section{INTRODUCTION}

In 1929, Howard C. Taylor first described a subset of epithelial ovarian tumors which he termed semi malignant. Ever since their description as a distinct entity in 1971, borderline ovarian tumors have puzzled investigators by their behavior which is intermediate between benign and malignant ovarian tumours. They occur in younger women and have a lower recurrence rate $(7 \%)$ and excellent 5-year survival $(95 \%)$ compared to epithelial ovarian cancers. ${ }^{1,2}$ Surgical staging for 
borderline tumours comprises of peritoneal washings for cytology, hysterectomy, bilateral salpingo oopherectomy and omentectomy. ${ }^{3}$

Appendicectomy is performed in case of mucinous tumours. Advanced disease stage has been found to worsen the prognosis. ${ }^{2}$ This study was done in an attempt to further clarify the behavior of these tumours in terms of factors affecting recurrence, and fertility outcome in patients attempting conception after conservative surgeries.

\section{METHODS}

The study was retrospective and included 56 patients diagnosed with borderline ovarian tumours during the period of 5 years from $1^{\text {st }}$ of January 2005 to $31^{\text {st }}$ December 2009 in Regional Cancer Centre, Thiruvananthapuram.

Patients who were operated outside and had their histopathology confirmed by pathologists in RCC and were later followed up in RCC were also included. Data was collected from hospital records and also from telephonic interviews for patients who were not under regular follow up. All patients were followed till December 2012.

\section{Pre-operative assessment}

All patients had pre-operative ultrasonography and determination of CA 125. Most patients also had a preoperative CT scan of the abdomen and pelvis.

\section{Surgery}

Standard surgery consisted of total abdominal hysterectomy, bilateral salpingo oopherectomy and omentectomy. Conservative surgery consisting of cystectomy or adnexectomy were done in patients who had not completed child bearing. Patients who had peritoneal implants underwent excision of involved peritoneum.

\section{Follow up and outcome}

Patients were examined every 3 months for the first year following the procedure, then 6 monthly for next 2 years and then annually. CA 125 and ultrasonogram was done at each visit. Patient characteristics, the type and number of recurrences and fertility results were analysed.

\section{Analysis}

Fischer's exact test was used to evaluate the association between variables. Univariate analysis was done to assess association between individual variables with disease free survival and recurrence.
Multiple logistic regression analysis was done to find out independent association of individual variables with recurrence.

\section{RESULTS}

Median follow up period was 52.5 months. 20 (35.7\%) patients had undergone surgery in Regional Cancer Centre, while $36(64.28 \%)$ patients were operated elsewhere. The main patient and disease characteristics are given in Table 1.

Table 1: The main patient and disease characteristics.

\begin{tabular}{|c|c|c|}
\hline Age & $\mathbf{N}$ & $\%$ \\
\hline$<20$ & 10 & 17.9 \\
\hline $20-29$ & 17 & 30.4 \\
\hline $30-39$ & 12 & 21.4 \\
\hline$>40$ & 17 & 30.4 \\
\hline Mean & 33. & \\
\hline \multicolumn{3}{|l|}{ CA 125} \\
\hline$<35 \mathrm{IU} / \mathrm{ml}$ & 36 & 64.3 \\
\hline$>35 \mathrm{IU} / \mathrm{ml}$ & 20 & 35.7 \\
\hline \multicolumn{3}{|c|}{ Histopathology } \\
\hline Serous & 23 & 41.1 \\
\hline Mucinous & 32 & 57.1 \\
\hline Endometroid & 1 & 1.8 \\
\hline \multicolumn{3}{|l|}{ Parity } \\
\hline Nulliparous & 20 & 35.7 \\
\hline Parous & 36 & 64.3 \\
\hline \multicolumn{3}{|l|}{ Ascites } \\
\hline Present & 7 & 12.5 \\
\hline Absent & 49 & 87.5 \\
\hline \multicolumn{3}{|l|}{ Size of tumour } \\
\hline $10 \mathrm{cms}$ & 13 & 23.2 \\
\hline$>10 \mathrm{cms}$ & 43 & 76.8 \\
\hline \multicolumn{3}{|l|}{ Bilaterality } \\
\hline Present & 11 & 19.6 \\
\hline Absent & 45 & 80.4 \\
\hline \multicolumn{3}{|c|}{ Stage of disease } \\
\hline Stage I & 48 & 85.7 \\
\hline Stage II & 2 & 3.6 \\
\hline Stage III & 6 & 10.7 \\
\hline \multicolumn{3}{|c|}{ Micropapillary histology } \\
\hline Present & 8 & 14.3 \\
\hline Absent & 48 & 85.7 \\
\hline \multicolumn{3}{|l|}{ Microinvasion } \\
\hline Present & 8 & 14.3 \\
\hline Absent & 48 & 85.7 \\
\hline \multicolumn{3}{|c|}{ Peritoneal implants } \\
\hline Present & 9 & 16.1 \\
\hline Absent & 47 & 83.9 \\
\hline \multicolumn{3}{|c|}{ Type of implants } \\
\hline Invasive & 1 & 11.1 \\
\hline Non-invasive & 8 & 88.9 \\
\hline
\end{tabular}




\section{Patient and tumour characteristics}

The mean age at the time of diagnosis was 33.5 yrs. 20 patients were nulliparous $(35.7 \%)$ while 36 were parous $(64.3 \%)$. The tumour was serous in 23 patients $(41.1 \%)$, mucinous in 32 patients $(57.1 \%)$ and endometrioid in 1 patient $(1.8 \%)$. Serum CA 125 was elevated in 20 patients $(35.7 \%)$ while it was within normal levels in 36 patients $(64.3 \%)$. Ascites was present in 7 patients $(12.5 \%)$.

The tumour was larger than $10 \mathrm{cms}$ in 43 patients $(76.8 \%)$ while it was smaller than $10 \mathrm{cms}$ in 13 patients (23.2\%). 48 patients (85.7\%) had Stage I disease, 2 patients had Stage II disease $(3.6 \%)$ and 6 patients had Stage III disease $(10.7 \%)$ at diagnosis. 8 patients had micropapillary disease $(14.3 \%)$ and 8 patients had microinvasion (14.3\%).

Peritoneal implants were present in 9 patients $(16.1 \%)$ of which 1 patient had invasive implants and 8 had noninvasive implants.

\section{Surgery}

Details of the surgical procedures and outcomes are given in Table 2. 29 patients $(51.8 \%)$ underwent complete surgery with hysterectomy, bilateral salpingo oopherectomy and omentectomy while 27 patients (48.2\%) had fertility sparing surgery. Of these 27 patients, 13 patients underwent unilateral cystectomy while 14 underwent unilateral adnexectomy. Tumour rupture occurred during surgery in 22 patients $(39.3 \%)$ while 34 patients had no rupture of the tumour. Post operatively adjuvant chemotherapy was given in two patients who had peritoneal implants. Recurrence of disease occurred in 17 patients $(30.4 \%)$ during the period of follow up, while 39 patients $(69.6 \%)$ were disease free at last follow up.
Table 2: Details of the surgical procedures and outcomes.

\begin{tabular}{|lll|}
\hline Surgery & N & $\%$ \\
\hline Conservative & & \\
\hline Radical & 27 & 48.2 \\
\hline Cyst rupture & 29 & 51.8 \\
\hline Yes & & \\
\hline No & 22 & 39.3 \\
\hline Chemotherapy received & 34 & 60.7 \\
\hline Yes & & \\
\hline No & 2 & 3.6 \\
\hline
\end{tabular}

\section{Follow up and outcome}

Median follow up period was 52.5 months. Recurrences were observed in 17 patients $(30.4 \%)$ during the entire course of follow up. The mean time to recurrence was $32.9+/-30.7$ months. 16 of the recurrences $(94.1 \%)$ were borderline whereas 1 was invasive $(5.9 \%)$. 15 of the patients $(88.2 \%)$ underwent surgery for recurrence, 1 $(5.9 \%)$ received chemotherapy and 1 (5.9\%) was followed up. At the end of follow up period, 50 patients $(89.3 \%)$ were alive and disease free, 5 patients $(8.9 \%)$ were alive with disease and 1 patient $(1.8 \%)$ had died of other causes.

\section{Factors affecting recurrence}

Out of 13 patients who were treated with a unilateral cystectomy, $9(69.2 \%)$ recurred and all of them recurred in the same ovary. Of the 14 patients who underwent a unilateral adnexectomy, $4(28.57 \%)$ recurred, 2 in the same ovary and 2 in the opposite ovary. 4 out of 28 patients $(14.28 \%)$, who underwent complete surgery recurred 1 in the same ovary and 3 in the peritoneum.

Table 3: Types of surgery.

\begin{tabular}{|lll|}
\hline Type of surgery & $\begin{array}{l}\text { Site of recurrence } \\
\text { Same ovary }\end{array}$ & Opposite ovary \\
\hline Cystectomy & $9(69.2 \%)$ & $2(14.2 \%)$ \\
\hline Ovariotomy & $2(14.2 \%)$ & \\
\hline Complete surgery & $1(3.57 \%)$ & $3(10.71 \%)$ \\
\hline
\end{tabular}

Table 4: Relationship between clinicopathologic features and recurrence.

\begin{tabular}{|c|c|c|c|c|}
\hline \multicolumn{2}{|l|}{ Variables } & \multirow{2}{*}{$\begin{array}{l}\text { Recurrence } \\
\text { Yes } \\
10(37 \%)\end{array}$} & \multirow{2}{*}{$\begin{array}{l}\text { No } \\
17(63 \%)\end{array}$} & \multirow{2}{*}{$\begin{array}{l}\mathrm{P} \\
0.386\end{array}$} \\
\hline Age & $<30$ & & & \\
\hline & $>=30$ & $7(24.1 \%)$ & $22(75.9 \%)$ & \\
\hline \multirow{2}{*}{ Histology } & Serous & $9(39.1 \%)$ & $14(60.9 \%)$ & 0.376 \\
\hline & Mucinous & $8(25 \%)$ & $24(75 \%)$ & \\
\hline \multirow[t]{2}{*}{ Micropapillary } & Yes & $5(62.5 \%)$ & $3(37.5 \%)$ & 0.047 \\
\hline & No & $12(25 \%)$ & $36(75 \%)$ & \\
\hline \multirow[t]{2}{*}{ Microinvasion } & Yes & $7(46.7 \%)$ & $8(53.3 \%)$ & 0.188 \\
\hline & No & $10(24.4 \%)$ & $31(75.6 \%)$ & \\
\hline \multirow[t]{2}{*}{ Peritoneal implants } & Yes & $7(77.8 \%)$ & $2(22.2 \%)$ & 0.002 \\
\hline & No & $10(21.3 \%)$ & $37(78.7 \%)$ & \\
\hline
\end{tabular}


In order to assess the various factors affecting recurrence, univariate and multivariate analysis was done. Univariate analysis showed a significant association between micro papillary histology, peritoneal implants and recurrence. On multivariate analysis, only peritoneal implants were found to be independently associated with recurrence.

\section{Fertility outcome}

Among the 27 women who underwent conservative surgery, 16 attempted conception of which 10 women had spontaneous conception and successful child births.

\section{DISCUSSION}

According to the WHO criteria, Borderline ovarian tumours are typically diagnosed by absence of stromal invasion. They have mitotic activity and nuclear abnormalities that are intermediate between benign and malignant epithelial ovarian cancers. Borderline ovarian tumours usually occur in a relatively younger age group compared to epithelial ovarian cancers. In the present study, the mean age at diagnosis was 33.5 yrs. This has been reported in several other studies. ${ }^{4,5}$ Serous borderline tumours constituted $41.1 \%$ and mucinous tumours constituted $57.1 \%$ among the patients in this study. A study by Link et al reported $50 \%$ serous tumours, $46 \%$ mucinous tumours and $3.9 \%$ mixed, endometrioid, clear cell or Brenner tumours. ${ }^{6} 64.3 \%$ of the patients in the study had atleast one child while $35.7 \%$ were nulliparous. CA 125 levels were raised in $35.7 \%$ patients, which included earlier stages.

In view of younger age at presentation and the relatively good prognosis in borderline ovarian tumours compared to epithelial ovarian cancers, fertility sparing surgery is considered in women who are yet to complete child bearing. In unilateral tumours, a unilateral adnexectomy is considered adequate. The present study shows a significantly higher rate of recurrence in the same ovary with ovarian cystectomy $(69.2 \%)$ compared to adnexectomy $(28.57 \%)$ which has been established in several other studies with recurrence rates of $12-58 \%$ for cystectomies and 0-20\% for adnexectomies. ${ }^{7-9}$ Hence, cystectomy should be considered only for bilateral tumours (with unilateral adnexecetomy) or in patients with only one ovary.

Microinvasive histology was found in $14.3 \%$ of patients in our study group. But the presence of microinvasion did not significantly increase the chances of recurrence in these patients. Several other studies too have shown that microinvasion does not increase the chances of recurrence or affect the survival. ${ }^{10,11}$ Micropapillary histology was also seen in $14.3 \%$ of patients. The presence of micropapillary disease was significantly associated with recurrence by univariate analysis, but was not found to be an independent risk factor on multivariate analysis. Studies have shown that micropapillary histology is more associated with advanced stages, invasive implants, higher recurrence rates and lower survival. ${ }^{12}$ Peritoneal implants were seen in $16.1 \%$ of the study population, and this was found to be significantly associated with recurrence by both univariate and multivariate analysis.

\section{CONCLUSION}

Borderline tumours have a very good prognosis compared to malignant epithelial ovarian tumours. Treatment is primarily surgical and consists of total abdominal hysterectomy, bilateral salpingo oopherectomy and omentectomy. Because the incidence of lymph node involvement has been found low, there is no established role for lymph node dissection as part of staging. But they are prone to recur especially in cases where complete surgery has not been done. Patients with high risk factors like micropapillary histology, peritoneal implants and history of ovarian cystectomy need to be closely followed up for early detection of recurrence. Recurrences are amenable to treatment with completion surgery.

\section{Funding: No funding sources}

Conflict of interest: None declared

Ethical approval: The study was approved by the Institutional Ethics Committee

\section{REFERENCES}

1. Winter WE, Kucera PR, Rodgers W. Surgical staging in patients with ovarian tumours of low malignant potential. Obstet Gynecol. 2002:100:671-6.

2. Trimble CL, Kosary C, Trimble EL, Long term survival and patterns of care in women with ovarian tumours of low malignant potential, Gynecol Oncol. 2002;86:34-7.

3. Menzin AW, Gal D, Lovecchio JL, Contemporary surgical management of borderline ovarian tumours: a survery of the Society of Gynecologic Oncologists, Gynecol Oncol. 2007;78:7-9.

4. Jie Ren, Zhilan Peng, Kaixuan Yang. A clinicopathologic multivariate analysis affecting recurrence of borderline ovarian tumours. Gynecol Oncol. 110(2008)162-7.

5. Kennedy AW, Hart WR. Ovarian papillary serous tumours of low malignant potential (serous borderline tumours): a long term follow up study including patients with micro invasion, lymph node metastasis and transformation to invasive serous carcinoma. Cancer. 1996:78;278-86.

6. Link CJ, Reed E, Sarosy G, Kohn E. Borderline ovarian tumours. Am J Med. 1996;101:217-25.

7. Morice P, Camatte S, Wicart-Poque F, Atallah D, Rouzier R, Pautier P, et al. Results of conservative management of epithelial malignant and borderline ovarian tumours. Hum Reprod Update. 2003;9:185

8. Poncelet C, Fauvet R, Boccara J, Darai E. Recurrence after cystectomy for borderline ovarian 
tumours: Results of a French Multicenter study. Annals Surg Oncol. 2006;13(4):565-71.

9. Palomba S, Zupi E, Russo T, Falbo A, Negro SD, Manguso F, et al. Comparison of two fertility sparing approaches for bilateral borderline tumours; a randomized controlled study. Human Reproduction 2007;22:578-85.

10. Hogg R, Scurry J, Kim SN, Friedlander M, Hacker N. Microinvasion links ovarian serous borderline tumour and grade I invasive carcinoma. Gynecol Oncol. 2007; 106:44-51.

11. Morris RT, Gershenson DM, Silva EG, Follen M, Morris M, Wharton JT. Outcome and reproductive function after conservative surgery for borderline ovarian tumours. Obstet Gynecol. 2009;95:541-7.

12. Smith Schdev AE, Schdev PS, Kurman RJ. Noninvasive and invasive micropapillary (low grade) serous carcinoma of the ovary; a clinicopathological analysis of 135 cases. Am J Surg Pathol. 2003;27:725-36.

Cite this article as: Dinesh D, Nair RP, Sambasivan S, Kumar A, Ahamed IM. Borderline ovarian tumours-patterns of recurrence and fertility outcome. Int J Reprod Contracept Obstet Gynecol 2017;6: 4269-73. 